\title{
HUBUNGAN POLA MAKAN DAN TINGKAT PENGETAHUAN DENGAN KADAR ASAM URAT DALAM DARAH PADA PENDERITA GOUT ARTRITIS DI PUSKESMAS RANOTANA WERU
}

\author{
Anisha M.G Songgigilan \\ Inneke Rumengan \\ Rina Kundre \\ Program Studi Ilmu Keperawatan Fakultas Kedokteran \\ Universitas Sam Ratulangi \\ Email : anishasulli@gmail.com
}

\begin{abstract}
Abstrack: Gout Arthritis is one of degenerative diseases that attacks joint marked by the increasing of uric acid level excessively inside the body, and when it is repeating chronically, it may cause thopi. The lack of society's knowledge about gout arthritis may lead to the emergence of this disease, where it also happens because of the eating pattern. Eating Pattern consists of the frequency of food, types of food, the purpose, eat, the function of food, and the way how was the food processed. The aim of this study is to know the relation between eating pattern \& knowledge extent of uric acid level of people with gout arthritis in public health center of ranotana weru's. Research method is using the cross sectional approach. The study involved 93 gout arthritis sufferers as the respondents by using purposive sampling technique. Data collected by using questionnaires. The result is using chi square in the level of significance $95 \%$ which values that significant value 0,000 $<0,05$ for eating pattern and 0,001 $<0,05$ Conclusion, there is a relation between eating pattern and uric acid level, and there is a relation between knowledge extent and uric acid level.
\end{abstract}

Keywords : Uric acid level, knowledge level, eating pattern

\begin{abstract}
Abstrak : Gout artritis merupakan salah satu penyakit degenerative yang menyerang sistem persendian dimana penyakit ini ditandai dengan peningkatan kadar asam urat dalam tubuh secara berlebihan dan gout artritis yang terjadi berulang atau bertahun akan menyebabkan timbulnya tophi. Kurangnya pengetahuan masyarakat tentang gout artritis bepengaruh terhadap terjadinya gout artritis, dimana salah satu faktor penyebab terjadinya gout artritis yaitu pola makan. Pola makan terdiri dari frekuensi makanan, jenis makanan, tujuan, makan, fungsi makanan, dan cara pengolahan makanan. Tujuan penelitian ini adalah mengetahui hubungan pola makan dan tingkat pengetahuan dengan kadar asam urat dalam darah pada penderita gout artritis di puskesmas ranotana weru. Metode penelitian menggunakan pendekatan cross sectional. Responden terdiri dari 93 penderita gout artritis dengan teknik pengambilan sampel dengan cara purposive sampling. Pengumpulan data menggunakan kuesioner. Hasil Uji penelitian dengan menggunakan uji chi-square pada tingkat kemaknaan 95\%, didapat bahwa nilai signifikan $0,000<0,05$ untuk pola makan dan 0,001 $<0,05$. Kesimpulan terdapat hubungan antara pola makan dengan kadar asam urat dalam darah dan terdapat hubungan antara tingkat pengetahuan dengan kadar asam urat dalam.
\end{abstract}

Kata kunci : Kadar asam urat, tingkat pengetahuan, pola makan

\section{PENDAHULUAN}

Meningkatnya taraf hidup masyarakat terutama di negara maju dan kota-kota besar dapat membawa perubahan pola hidup mereka. Perubahan pola hidup dapat mempengaruhi status kesehatan individu dan membawa perubahan pola penyakit, terutama penyakit yang 
berhubungan dengan gaya hidup. Kondisi tersebut mengubah pola penyakit yang pada awalnya hanya didominasi oleh penyakit infeksi, namun sekarang bergeser pada penyakit degeneratif dan metabolik yang meningkat. (Tumenggung, 2015). Salah satu penyakit degenerative yang sering terjadi yaitu penyakit gout artritis dimana terjadi penumpukan asam urat dalam tubuh secara berlebihan hiperurisemia (Anies, 2018). Penyakit asam urat akan menacapai puncak pada usia 40 tahun ke atas. Pada wanita, resiko gout artritis akan meningkat setelah menopause. Purba dkk, 2015 menjelaskan bahwa pada wanita terdapat hormone estrogen yang membantu memperlancar proses pembuangan asam urat dalam ginjal.

Jaliana dkk (2018) menyatakan di dunia penderita gout artritis mengalami kenaikan jumlah penderita hingga dua kali lipat antara tahun 1990-2010. Pada orang dewasa di Amerika Serikat penyakit gout mengalami peningkatan dan mempengaruhi 8.3 juta (4\%) orang Amerika. Sedangkan prevalensi hiperurisemia juga meningkat dan mempengaruhi $43.300 .000 \quad(21 \%)$ orang dewasa di Amerika Serikat. Penelitian di Taiwan tahun 2013 prevalensi penyakit gout artritis sebesar $41,4 \%$ dan meningkat sebesar $0,5 \%$ setiap tahun. Penyakit gout artritis diperkirakan terjadi pada 840 orang dari setiap 100.000 orang. Prevalensi penyakit gout artritis di Indonesia terjadi pada usia di bawah 34 tahun sebesar $32 \%$ dan di atas 34 tahun sebesar $68 \%$ ). Berdasarkan hasil Kemenkes (2013) menunjukkan bahwa penyakit sendi di Indonesia yang diagnosis tenaga kesehatan (nakes) sebesar 11.9\% dan berdasarkan diagnosis dan gejala sebesar $24.7 \%$, sedangkan berdasarkan daerah di Nusa Tenggara Timur 33,1\%, diikuti Jawa barat $32,1 \%$ dan Bali $30 \%$. Prevalensi penyakit sendi berdasarkan provinsi, prevalensi untuk Sulawesi Utara berdasarkan diagnosis tenaga kesehatan sebesar $10,3 \%$ dan berdasarkan diagnosis tenaga kesehatan ditambah gejala klinik sebesar $19,1 \%$. Sesorang yang mengalami asam urat (gout artritis) dapat disebabkan oleh beberapa faktor, salah satunya yaitu pola makan yang tidak terkontrol dan sering mengkonsumsi makanan yang mengandung purin tinggi, yang mengakibatkan kadar asam urat dalam darah meningkat (Anies,2018). Berbagai upaya dilakukan untuk mencegah penyakit gout artritis, pencegahan dapat di lakukan dengan menjauhi makanan dan minuman yang dapat memicu penyakit asam urat, menurunkan berat badan, dan cukup minum air putih. Pencegahan terhadap suatu penyakit akan lebih diperhatikan oleh seseorang yang mempunyai pengetahuan dan pengetahuan dapat diperoleh dari berbagai sumber informasi diantaranya melalui penyuluhan atau pendidikan kesehatan (Ulfiyah, 2013). Pengetahuan merupakan hasil dari tahu atau memperoleh informasi dan membentuk suatu tindakan (Notoatmodjo, 2012). Penelitian sebelumnya oleh Hambatara dkk, 2018 melaporkan bahwa mengkonsumsi makanan yang tinggi purin dapat menyebabkan peningkatan kadar asam urat dalam darah.

Penelitian sebelumnya oleh Oga, dkk (2017) melaporkan bahwa ada hubungan antara tingkat pengetahuan dan pola makan dengan kejadian gout artritis. Berdasarkan studi pendahuluan yang dilakukan pada tanggal 7 Oktober 2018 di Puskesmas Ranotana Weru, dengan hasil wawancara yang dilakukan pada 10 orang diketahui, sebanyak 8 dari 10 orang memiliki pola makan yang tidak teratur dengan frekuensi makanan yang banyak dan sering mengkonsumsi makanan seperti tempe dan tahu, kangkung, daging, ikan sarden dan alkohol. Sedangkan 2 yang lainnya diketahui memiliki pola makan yang teratur. Hasil wawancara juga didapatkan 10 orang tersebut pernah mengalami nyeri pada sendi jari kaki dan tangan, lutut pergelangan kaki. Dimana gejala tersebut merujuk pada tanda dan gejala gout artritis.

Berdasarkan hasil wawancara yang juga dilakukan pada 10 orang, diketahui 6 
dari 10 orang memiliki pengetahuan yang kurang tentang penyakit gout artritis. Sedangkan 4 orang lainnya diketahui memiliki pengetahuan yang cukup tentang gout artritis. Hasil wawancara juga didapatkan bahwa sebagian masyarakat yang menderita gout artritis masih berperilaku kurang dalam pencegahan diantaranya mereka masih mengkonsumsi makanan tinggi purin dalam jumlah banyak. Berdasarkan fenomena diatas, maka peneliti ingin melakukan penelitian dengan tentang hubungan pola makan dengan tingkat kejadian gout artritis di Puskesmas Ranotana Weru. Dilihat dari fenomena yang terjadi saat ini, pola makan dan tingkat pengetahuan sangat berdampak pada kadar asam urat. Sehingga, berdasarkan hal diatas saya tertarik untuk melakukan penelitian mengenai "Hubungan Pola Makan Dan Tingkat Pengetahuan Dengan Kadar Asam Urat Pada Penderita Gout Artritis Di Puskesmas Ranotana Weru".

\section{METODE PENELITIAN}

Penelitian ini termasuk dalam jenis penelitian kuantitatif dengan menganalisis gambaran hubungan antara kedua variabel yaitu variabel independen (Pola makan dan tingkat pengetahuan) dan variabel dependen (Kadar asam urat dalam darah). Penelitian ini menggunakan desain penelitian cross sectional. Penelitian ini dilaksanakan di Puskesmas Ranotana Weru pada tanggal 21 Januari 2019. Populasi penelitian ini adalah seluruh penderita gout artritis 106. Pengambilan sampel menggunakan teknik purposive sampling dengan rumus slovin maka didapatkan jumlah sampel minimal 84, untuk mengantisipasi hilangnya unit sampel maka digunakan rumus dropout sehingga sampel yang didapatkan berjumlah 93 penderita gout artritis. Instrumen penelitian yang digunakan untuk mengukur variabel pola makan menggunakan kuesioner yang digunakan sebelumnya oleh Tumenggung (2012) yang telah diuji validitasnya. Kuesioner ini terdiri dari 22 pertanyaan. Pertanyaan dibagi per topic, 2 topik (jenis dan jumlah makanan) terdiri dari 7 pertanyaan dan 1 topic (frekuensi makan) terdiri dari 8 pertanyaan, total ada 3 topik dan dikategorikan $0=$ tidak baik $1=$ baik. Pengukuran tingkat pengetahuan menggunakan kuesioner yang telah digunakan sebelumnya oleh Ulfiyah (2013) yang telah diuji validitasnya. Terdiri dari 20 pernyataan mengenai gout artritis. 15 pernyataan positif dan 5 penataan negative dan di kategorikan $0=$ kurang, 1=cukup, $2=$ baik. Variable kadar asam urat dalam darah menggunakan Uric Acid Meter dengan kriteria skor $0=$ tidak untuk tidak normal laki-laki $>7 \mathrm{mg} / \mathrm{dL}$ untuk perempuan $>6 \mathrm{mg} / \mathrm{dL}, 1=$ normal untuk laki-laki 3,4-7 mg/dL untuk perempuan 2,4$6 \mathrm{mg} / \mathrm{dL}$.

Pengolahan data yang diperoleh dari hasil penelitian ini diolah secara manual dengan mengelompokkan hasil wawancara dan observasi kemudian dilakukan penghitungan skor dan dianalisis menggunakan uji statistik melalui sistem komuterisasi dengan beberapa tahap yaitu editing, coding, entering, cleaning (Notoatmodjo, 2012). Analisa bivariat dalam penelitian ini yaitu untuk mengetahui hubungan pola makan dan tingkat pengetahuan dengan kadar asam urat pada penderita gout artritis di Puskesmas Ranotana Weru. Peneliti menggunakan uji statistic Pearson Chi Square dengan tingkat kemaknaan $95 \%(\alpha=0,05)$.

\section{HASIL dan PEMBAHASAN}

\section{Karakteristik Responden}

Tabel 1. Distribusi Responden Berdasarkan Usia

\begin{tabular}{ccc}
\hline Usia & $\mathbf{n}$ & $\mathbf{\%}$ \\
\hline $\begin{array}{l}\text { Dewasa Akhir } \\
\text { (36-45 tahun) }\end{array}$ & 5 & 5,4 \\
$\begin{array}{l}\text { Lansia Awal } \\
\text { (46-55 tahun) }\end{array}$ & 40 & 43,0 \\
$\begin{array}{c}\text { Lansia Akhir } \\
\text { (56-65 tahun) }\end{array}$ & 48 & 51,6 \\
\hline Total & $\mathbf{9 3}$ & $\mathbf{1 0 0}$ \\
\hline
\end{tabular}

Sumber : Data Primer 2019 
Hasil penelitian didapatkan bahwa dari 93 responden sebagian besar berasal dari kelompok usia 55-65 tahun yaitu sebanyak 48 (51,6\%). Dari data yang diperoleh di buku register Puskesmas Ranotana Weru bahwa sebagian besar pasien yang datang berkunjung adalah pasien dengan usia lanjut. Hal ini sesuai dengan teori Maryam dkk (2008) yang menjelaskan bahwa perubahan metabolisme pada usia lanjut seperti sistem perkemihan dan endokrin, dimana menurunnya laju filtrasi glomerulus, ekskresi dan reabsorbsi oleh ginjal, dan terjadi penurunan produksi hormone seperti progesterone, estrogen dan testosterone.

Tabel 2. Distribusi Responden Berdasarkan Jenis Kelamin

\begin{tabular}{ccc}
\hline Jenis Kelamin & n & \% \\
\hline Laki-laki & 37 & 39,8 \\
Perempuan & 56 & 60,2 \\
\hline Total & $\mathbf{9 3}$ & $\mathbf{1 0 0}$
\end{tabular}

Sumber : Data Primer 2019

Hasil penelitian didapatkan bahwa dari 93 responden sebagian besar berjenis kelamin perempuan sebanyak 56 orang (60,2\%). Dari data yang diperoleh di buku register Puskesmas Ranotana Weru bahwa sebagian besar pasien yang datang berkunjung adalah perempuan. Anies (2018) menjelaskan bahwa perempuan menopause lebih beresiko terkena gout artritis karena terjadi penurunan hormone estrogen.

Tabel 3. Distribusi Responden Berdasarkan Pendidikan

\begin{tabular}{cll}
\hline Pendidikan & $\mathbf{n}$ & $\mathbf{\%}$ \\
\hline SD - SMP & 51 & 54,8 \\
SMA - Perguruan & 42 & 45,3 \\
Tinggi & & \\
\hline Total & $\mathbf{9 3}$ & $\mathbf{1 0 0}$ \\
\hline
\end{tabular}

Sumber : Data Primer 2019

Hasil penelitian didapatkan bahwa dari 93 responden sebagian besar responden memilki tingkat pendidikan SD - SMP sebanyak 51 orang $(54,8 \%)$. Data yang diperoleh di Puskesmas Ranotana Weru dimana sebagian responden hanya menyelesaikan pendidikan sampai tingkat SMP, dikarenakan berbagai factor seperti pernikahan usia dini, masalah keuangan, dan masalah keluarga. Kadir (2012) menjelaskan bahwa pendidikan dapat mempengaruhi proses belajar, makin tinggi pendidikan seseorang makin mudah orang tersebut untuk menerima informasi, baik dari orang lain maupun dari media massa.) sehingga pendidikan berpengaruh terhadap tingkat pengetahuan seseorang (Perry dan Potter, 2005).

Tabel 4. Distribusi Responden Berdasarkan Konsumsi Air Minum

\begin{tabular}{ccc}
\hline $\begin{array}{c}\text { Konsumsi Air } \\
\text { Minum }\end{array}$ & n & \% \\
\hline$\geq 8$ Gelas & 27 & 29,0 \\
$<8$ Gelas & 66 & 71,0 \\
\hline Total & $\mathbf{9 3}$ & $\mathbf{1 0 0}$ \\
\hline
\end{tabular}

Sumber : Data Primer 2019

Hasil penelitian didapatkan bahwa dari 93 responden sebagian responden mengkonsumsi air minum $<8$ gelas terbanyak sebanyak 66 orang $(71,0 \%)$. Konsumsi air minum yang banyak $(\geq 8$ gelas per hari) dapat membantu pengeluaran asam urat sehingga dapat menurunkan kadar asam urat dalam darah (Nurhamidah \& Nofiani, 2015). Asam urat diekresikan di ginjal dan dikeluarkan lewat urin, melalui 3 tahapan yaitu; filtrasi, reasorbsi, dan augmentasi selanjutnya selanjutnya urin yang dihasilkan akan dikeluarkan dari tubuh (Furqonita, 2006).

\section{Analisa Univariat}

Tabel 5. Distribusi Responden Berdasarkan Pola Makan

\begin{tabular}{ccc}
\hline Pola Makan & n & \% \\
\hline Tidak Baik & 71 & 76,3 \\
Baik & 22 & 23,7 \\
\hline Total & $\mathbf{9 3}$ & $\mathbf{1 0 0}$ \\
\hline
\end{tabular}

Sumber : Data Primer 2019 
Hasil penelitian dapat diketahui bahwa dari 93 responden sebagian besar memiliki pola makan tidak baik dengan jumlah 71 orang $(76,3 \%)$, yang digambarkan dari hasil penelitian dimana kebanyakan responden mengkonsumsi makanan seperti daging, tahu tempe dan kangkung dalam sehari bisa $>70$ gr daging, $>150$ gr tahu tempe, dan sebagainya dan dalam seminggu $>3$ kali mengkonsumsi makanan tersebut. Hasil penelitian ini sejalan dengan Tumenggung (2015) dimana 42 responden 24 orang $(57,1 \%)$ diantaranya memiliki pola makan tidak baik. Hal ini menunjukkan bahwa pola makan dengan asupan purin tinggi dapat meningkatkan resiko terjadinya penyakit gout artritis (Ilyas dkk, 2014).

Tabel 6. Distribusi Responden Berdasarkan Tingkat Pendidikan

\begin{tabular}{ccc}
\hline Pengetahuan & n & \% \\
\hline Kurang & 39 & 41,9 \\
Cukup & 23 & 24,7 \\
Baik & 31 & 33,3 \\
\hline Total & $\mathbf{9 3}$ & $\mathbf{1 0 0}$ \\
\hline
\end{tabular}

Sumber : Data Primer 2019

Hasil penelitian didapatkan bahwa dari 93 sebagian besar memilki tingkat pengetahuan kurang dengan jumlah 39 orang $(41,9)$, yang digambarkan dari hasil penelitian dimana kebanyakan responden berpendapat bahwa penyakit gout artritis adalah penyakit akibat pengapuran sendi dan berpendapat bahwa penyakit gout artritis dapat disembuhkan, tidak mengetahui bahwa minum banyak air putih dapat mengurangi kadar asam urat dan mencegah penyakit gout artritis, dan tidak mengetahui bahwa komplikasi dari gout artritis adalah batu ginjal. Hasil penelitian ini sejalan dengan Oga dkk (2017) dimana 49 responden 35 orang $(71 \%)$ diantaranya memiliki tingkat pengetahuan yang kurang. Pengetahuan merupakan hasil dari tahu dan ini terjadi setelah orang melakukan penginderaan terhadap suatu objek tertentu, dimana proses tersebut dipengaruhi oleh intensitas perhatian dan persepsi terhadap, sehingga pengetahuan menjadi domain yang penting untuk terbentuknya tindakan seseorang (Notoatmodjo, 2012).

Tabel 7. Distribusi Responden Berdasarkan Kadar Asam Urat Dalam Darah

\begin{tabular}{ccc}
\hline $\begin{array}{c}\text { Kadar Asam } \\
\text { Urat Darah }\end{array}$ & n & \% \\
\hline Tidak Normal & 69 & 74,2 \\
Normal & 24 & 25,8 \\
\hline Total & $\mathbf{9 3}$ & $\mathbf{1 0 0}$ \\
\hline
\end{tabular}

Sumber : Data Primer 2019

Hasil penelitian didapatkan bahwa dari 93 sebagian besar memilki kadar asam urat tidak normal berjumlah 69 (74,2\%), yang dilihat dari hasil pengukuran yang dilakukan peneliti dengan menggunakan alat Uric Acid Hasil penelitian ini sejalan dengan Hasil ini sejalan dengan Purba dkk (2015) dimana 39 responden 28 diantaranya memiliki kadar asam urat tinggi. Salah satu tanda dan gejala penyakit gout artritis yaitu terjadi peningkatan kadar asam urat dalam darah (hiperurisemia) (Tumenggung, 2015). Dimana batasan normal kadar asam urat pada wanita 2,4-6 mg/dL sedangkan untuk pria 3,4-7 $\mathrm{mg} / \mathrm{dL}$ dan dikatakan tidak normal jika kadar asam urat pada wanita $>6$ $\mathrm{mg} / \mathrm{dL}$ sedangkan untuk pria $>7 \mathrm{mg} / \mathrm{dL}$ (Herliana, 2013).

\section{Analisa Bivariat}

Tabel 10. Hubungan Pola Makan Dengan Kadar Asam Urat Dalam Darah

\begin{tabular}{|c|c|c|c|c|c|c|c|}
\hline \multirow{3}{*}{$\begin{array}{c}\text { Pola } \\
\text { Makan }\end{array}$} & \multicolumn{4}{|c|}{ Kadar Asam Urat } & & & \multirow{3}{*}{$\begin{array}{l}\mathbf{P} \\
\mathbf{v}\end{array}$} \\
\hline & \multicolumn{2}{|c|}{$\begin{array}{c}\text { Tidak } \\
\text { Normal }\end{array}$} & \multicolumn{2}{|c|}{ Normal } & \multicolumn{2}{|c|}{ Jumlah } & \\
\hline & $\mathrm{n}$ & $\%$ & $\mathrm{n}$ & $\%$ & $\mathrm{n}$ & $\%$ & \\
\hline $\begin{array}{l}\text { Tidak } \\
\text { Baik }\end{array}$ & 67 & 97,1 & 4 & 16,7 & 71 & 76,3 & $0,00 \mathrm{C}$ \\
\hline Baik & 2 & 2,9 & 20 & 83,3 & 22 & 23,7 & \\
\hline
\end{tabular}

Sumber : Data Primer 2019 
Analisa hubungan antara pola makan dengan kadar asam urat dalam darah di Puskesmas Ranotana Weru dengan hasil uji Pearson Chi square dengan taraf signifikasi $\alpha=5 \%$ diperoleh $\rho$ value $=0,000$ $>0,05$. Hal ini menunjukkan tidak terdapat hubungan yang signifikan antara pola makan dengan kadar asam urat dalam darah di Puskesmas Ranotana Weru. Penelitian ini sesuai dengan Tumenggung (2015) menjelasakan bahwa terdapat hubungan antara pola makan dengan kejadian gout artritis.

Menurut Adriani (2016) pola makan merupakan suatu cara dalam pengaturan jumlah dan jenis makanan dengan maksud tertentu, dengan mengatur pola makan seseorang dapat seseorang dapat membantu mempertahankan kesehatan, status nutrisi dan mencegah atau membantu dalam proses kesembuhan penyakit. Pola makan seseorang dapat dilihat melalui jumlah, frekuensi, jenis, fungsi, dan cara pengolahan makan tersebut (Wijayanti dan Untari, 2017). Pola makan yang tidak baik atau tidak teratur seperti mengkonsumsi makanan cepat saji, minuman beralkohol terlebih lagi terlalu sering mengkonsumsi makanan yang mengandung purin tinggi secara berlebihan dapat mempengaruhi kadar asam urat dalam darah. Hal ini diperkuat dalam buku yang ditulis oleh (Anies, 2018) dimana pola makan yang tidak baik dapat mempengaruhi kadar asam urat dalam darah. Sependapat, Wijayanti dan Untari (2017) mengatakan bahwa pola makan menjadi salah satu penyebab penyakit gout artritis. Dalam penelitian yang dilakukan oleh Hambatara dkk (2018) mengatakan bahwa ada hubungan antara konsumsi asupan makanan yang mengandung purin dengan kejadian asam urat.

Berdasarkan hasil penelitian pola makan responden dapat dibuktikan dengan 3 point pertanyaan dalam kuesioner yaitu jenis, jumlah, dan frekuensi makanan. Dimana ketiga subitem tersebut dapat mengukur pola makan dari seseorang, dilihat dari jenis makanan yang dimakan, jumlah makanan yang dikonsumsi dan seberapa banyak frekuensi dari makanan yang akan dimakan. Menurut Wijayanti dan Untari (2017) mengatakan hal-hal tersebut merupakan yang paling utama dalam menentukan pola makan dari seseorang. Pola makan yang baik dapat mengurangi factor resiko penyakit gout artritis (Anies, 2018), salah satu pencegahan yang dapat dilakukan yaitu dengan mengatur pola makan, dimana pola makan seseorang dapat diimbangi dengan makanan yang mengandung gizi seimbang seperti makanan pokok, lauk pauk, sayur dan buah (Hanifah, 2011).

Tabel 11. Hubungan Pola Asuh Orang Tua Dengan Tingkat Pengetahuan

\begin{tabular}{ccccccccc}
\hline \multirow{2}{*}{$\begin{array}{c}\text { Tingkat } \\
\text { Pengetahuan }\end{array}$} & \multicolumn{9}{c}{ Kadar Asam Urat } & \multirow{2}{*}{$\begin{array}{c}\text { Tidak } \\
\text { Normal }\end{array}$} & \multicolumn{2}{c}{ Normal } & & & \multirow{2}{*}{ Pumlah } \\
\cline { 2 - 6 } & $\mathrm{n}$ & $\%$ & $\mathrm{n}$ & $\%$ & $\mathrm{n}$ & $\%$ & \\
\hline Kurang & 37 & 53,6 & 2 & 8,3 & 39 & 41,9 & \\
Cukup & 13 & 18,8 & 10 & 41,7 & 23 & 24,7 & 0,001 \\
Baik & 19 & 27,5 & 12 & 50,0 & 31 & 33,0 & \\
\hline
\end{tabular}

Sumber : Data Primer 2019

Hasil crosstab mengenai hubungan antara tingkat pengetahuan dengan kadar asam urat dalam darah di Puskesmas Ranotana Weru dengan hasil uji Pearson Chi square dengan taraf signifikasi $\alpha=5 \%$ diperoleh $\rho$ value $=0,001<0,05$. Hal ini menunjukkan terdapat hubungan yang signifikan antara tingkat pengetahuan dengan kadar asam urat dalam darah di Puskesmas Ranotana Weru. Pengetahuan merupakan hasil dari tahu dan ini terjadi setelah orang melakukan penginderaan terhadap suatu objek tertentu, dimana proses tersebut dipengaruhi oleh intensitas perhatian dan persepsi terhadap, sehingga pengetahuan menjadi domain yang penting untuk terbentuknya tindakan seseorang (Notoatmodjo, 2012). Pengetahuan sendiri dapat dipengaruhi oleh berbagai hal seperti pendidikan, informasi/ media massa, social, budaya, dan ekonomi, lingkungan, pengalaman, dan usia (Budiman dan Riyanto, 2013). 
Pengetahuan yang kurang dapat mempengaruhi seseorang untuk memahami proses dari penyakit gout artritis, sehingga responden tidak terlalu memahami proses dari penyakit gout artritis. Salah satunya responden tidak terlalu memahami cara pencegahan pencegahan penyakit gout artritis, karena kurangnya informasi tentang gout artritis. Dibuktikan dengan hasil penelitian yang telah dilakukan dimana penderita gout artritis paling banyak memilki pola makan yang tidak baik $(57,1 \%)$ dan jumlah konsumsi air minum < 8 gelas terbanyak berjumlah $(71,0 \%)$, ditambah dengan kejadian gout artritis yang dilihat dari kadar asam urat tidak normal paling banyak $(74,2 \%)$. Hal-hal diatas termasuk dalam pencegahan penyakit gout artritis. Sehingga dapat dilihat bahwa responden kurang memahami cara pencegahan dari penyakit gout artritis. Sebaliknya seseorang yang memilki pengetahuan yang baik pasti akan memahami cara pencegahan dari penyakit gout artritis.

Berdasarkan hasil penelitian ini juga didapatkan bahwa responden dengan pengetahuan cukup dan baik, memilki responden dengan kadar asam urat tidak normal lebih banyak. Hal ini menunjukkan bahwa responden yang memiliki pengetahuan yang luas tentang penyakit gout artritis belum tentu dapat mengaplikasikan pengetahuan tersebut ke dalam suatu tindakan, sehingga hal tersebut berpengaruh dalam perilaku responden dalam melakukan berbagai upaya pencegahan penyakit. Penelitian ini sejalan dengan Ulfiyah (2013) menjelasakan bahwa responden yang memilki pengetahuan baik tetapi peilaku pencegahan yang buruk dapat dipengaruhi oleh kondisi yang ada pada diri sendiri. Penelitian ini sejalan dengan Notoatmodjo (2012) menjelaskan bahwa tingkatan pengetahuan seseorang terdiri dari tahu, memahami, aplikasi, analisis, sintesis, dan evaluasi Pengetahuan seseorang dapat diperoleh melalui pendidikan formal dan pendidikan non formal. Pengetahuan sendiri juga bisa di peroleh melalui berbagai pengalaman dari orang tersebut. Sehingga pengetahuan juga dapat mempengaruhi dalam pengambilan suatu tindakan (Notoatmodjo,2012).

\section{SIMPULAN}

Pola makan merupakan salah satu factor yang mempengaruhi kadar asam urat dalam darah dan tingkat pengetahuan merupakan hal yang berpengaruh dalam pengambilan suatu tindakan Hal tersebut dibuktikan dengan hasil penelitian mayoritas penderita gout artritis memiliki pola makan tidak baik, tingkat pengetahuan yang kurang dan memiliki kadar asam urat tidak normal.

\section{DAFTAR PUSTAKA}

Adriani, M., Wirjatmadi, B. (2016). Pengantar Gizi Masyarakat. Jakarta: Prenada Media

Anies.

(2018). PENYAKIT DEGENERATIF: Mencegah \& Mengatasi Penyakit Degeneratif dengan Perilaku \& Gaya Hidup Modern yang Sehat. Yogyakarta: Ar-Ruzz Media.

Budiman \& Riyanto A (2013). Kapita Selekta Kuisioner Pengetahuan Dan Sikap Dalam Penelitian Kesehatan. Jakarta : Salemba Medika

Furqonita, D. (2006). Seri IPA BIOLOGI. Yudhistira Ghalia Indonesia

Hambatara, S. A., Sutriningsih, A., \& Warsono, W. (2018). Hubungan Antara Konsumsi Asupan Makanan Yang Mengandung Purin Dengan Kadar Asam Urat Pada Lansia Di Desa Tulungrejo Kecamatan Ngantang . Nursing News: Jurnal Ilmiah Mahasiswa Keperawatan, 3(1).

Hanifah. E. (2011). Cara Hidup Sehat. Jakarta: PT Balai Pustaka (Persero) 
Ilyas, N. O., Suprihartono, F. A., \& Dewi, M. (2014). Beberapa Faktor yang Berhubungan dengan Kejadian Hiperurisemia pada Pasien Rawat Jalan di RS Dustira Cimahi. GIZI INDONESIA, 37(2), 91-100.

Jaliana, J., \& Suhadi, S. (2018). FaktorFaktor Yang Berhubungan Dengan Kejadian Asam Urat Pada Usia 2044 Tahun Di Rsud Bahteramas Provinsi Sulawesi Tenggara Tahun 2017. Jurnal Ilmiah Mahasiswa Kesehatan Masyarakat, 3(2).

Kadir, A (2015). Dasar-Dasar Pendidikan Edisi Pertama. Jakarta: PRENADAMEDIA GROUP

Kemenkes. (2013). Riset Kesehatan Dasar. Jakarta: Badan Penelitian dan Pengembangan Kesehatan

Maryam, R. Siti, dkk. (2008). Mengenal Usia lanjut dan Perawatannya. Jakarta : Salemba Medika

Notoatmodjo (2012). Metodologi Penelitian Kesehatan. Jakarta : Rineka Cipta.

Nurhamidah, N., \& Nofiani, S. (2015). Faktor-faktor yang Berhubungan dengan Kejadian Asam Urat pada Pasien Rawat Jalan di Rumah Sakit Stroke Nasional Bukittinggi Tahun 2015. JURNAL KESEHATAN PERINTIS (Perintis's Health Journal), 2(4).

Oga, C., Hadi, M., \& Makausi, E (2017). Hubungan Pengetahuan Dan Pola Makan Dengan Kejadian Gout Artritis Pada Lansia Di Puskesmas Tinoor Kecamatan Tomohon Utara Kota Tomohon. Jurnal Online UNSRIT.
Perry dan Potter. Buku Ajar Fundamental Keperawatan. Jakarta: EGC. 2005

Purba, R. B., Rumagit, F., \& Loleh, N. P. (2015). Pola Makan Dan Kadar Asam Urat pada Wanita Menopause Yang Menderita Gout Arthritis Dipuskesmas Tikala Baru Manado. Jurnal GIZIDO, 7(1).

Talarima, B., Amiruddin, R., \& Arsin, A. A. (2012). Faktor risiko "gouty arthritis" di kota masohi kabupaten Maluku tengah tahun 2010. Makara Kesehatan, 16(2), 89-94.

Tumenggung, I. (2015). Hubungan Pola Makan Dengan Kejadian Gout Artritis DiRsud Toto Kabila Kabupaten Bone Bolango. Journal Health And Nutritions, 1 (2), 1-12.

Ulfiyah, H. (2013). Hubungan antara Tingkat Pengetahuan dengan Perilaku Wanita Menopause dalam Upaya Pencegahan Penyakit Gout di Kelurahan Pisangan.

Wijayanti, T., \& Untari, I. (2017). Hubungan Antara Pola Makan Dengan Penyakit Gout. URECOL 